\title{
Partidos e Comissões no Presidencialismo de Coalizão*
}

\author{
Fabiano Santos
}

\section{INTRODUÇÃO}

$\mathrm{O}$

ponto de partida de toda análise sobre os partidos brasileiros no Legislativo deve ser o conceito de "presidencialismo de coalizão". A combinação de sistema presidencialista, representação proporcional de lista aberta e sistema parlamentar fragmentado leva o chefe do Executivo, na intenção de implementar sua agenda de políticas públicas, a distribuir pastas ministeriais entre membros dos principais partidos, na esperança de obter em troca o apoio da maioria do Congresso $^{1}$. Contudo, no que se refere à lógica do comportamento partidário, o consenso entre os estudiosos acaba aí; pode-se dizer que existe um cisma básico entre duas perspectivas principais: a primeira afirma que os partidos no Brasil são indisciplinados e por isso o comportamento da Câmara é imprevisível. Além disso, argumenta-se que os deputados brasileiros estão sempre buscando transferir benefícios para seus redutos eleitorais, o que converte o Executivo em uma espécie de prisioneiro dos interesses localistas dos parlamentares (ver Ames, 1995; 2000; Amorim Neto, 1998; Geddes, 1994; Lamounier,

* [A tradução do original em inglês "Parties and Committees in the Coalition Presidential System" é de Vera Pereira.]

DADOS - Revista de Ciências Sociais, Rio de Janeiro, Vol. 45, nํ2, 2002, pp. 237 a 264. 
1991; Mainwaring, 1997; 1999; Samuels, 1998). A segunda abordagem defende posição oposta, isto é, que o comportamento dos partidos é disciplinado, as decisões da Câmara são previsíveis e seus membros não são capazes de fazer valer suas prodigalidades particularistas (ver Figueiredo e Limongi, 1999; Meneguello, 1998; Pereira, 2000; Santos, 1997) ${ }^{2}$.

Ambas as perspectivas revelam traços importantes do Legislativo brasileiro. De um lado, é razoável sustentar que os legisladores brasileiros têm interesses particularistas e, na maioria das vezes, se esforçam para construir uma boa reputação pessoal a despeito de sua filiação partidária. De outro, também é verdade que, após a promulgação da Constituição de 1988, os partidos brasileiros passaram a exibir um grau razoável de disciplina nas votações nominais no plenário. Ademais, há indicações de que o conflito político na Câmara se estrutura em linhas partidárias. Em outras palavras, se examinarmos o comportamento dos deputados em plenário é possível discernir claramente uma clivagem básica entre os partidos governistas e os partidos de oposição. É intenção deste artigo mostrar que ambas as perspectivas apresentam lacunas teóricas e empíricas.

Para começar, é preciso notar que as duas abordagens trabalham com um período limitado de tempo - somente o pós-88 é examinado com mais detalhes, isto é, as variações longitudinais são descartadas de saída. No caso brasileiro isto é especialmente grave, porque grande número de estudos alude aos incentivos que emanam dos sistemas eleitoral e de governo como as principais causas de uma "conduta" indisciplinada dos partidos ${ }^{3}$. Na realidade, os sistemas eleitoral e de governo dos períodos 1946-64 e pós-88 são idênticos, ambos baseiam-se na representação proporcional - RP de lista aberta e no sistema presidencialista. Portanto, se percebemos uma variação significativa na lógica da ação dos partidos entre um período e outro, pode-se alegar que é preciso acrescentar à explicação um elo necessário e, ainda mais, que os sistemas eleitoral e de governo não são capazes de tornar inteligíveis aspectos fundamentais de tal comportamento.

Em segundo lugar, embora seja verdade que alguns estudiosos chamam a atenção para a importância de variáveis procedimentais, principalmente no que diz respeito à primazia do presidente sobre o Congresso no processo decisório, também é fato que ainda não somos capazes de identificar o nexo lógico entre o aumento do controle do pre- 
sidente sobre a agenda legislativa e variações positivas na previsibilidade do comportamento parlamentar. Em outras palavras, o mecanismo pelo qual o controle da agenda por parte do presidente se traduz em um domínio mais amplo das lideranças sobre os deputados permanece ignorado. Sabe-se que os líderes partidários gozam de vantagens estratégicas no processo de encaminhamento dos projetos de lei à votação em plenário; no entanto, ainda não se conhecem as motivações dos deputados para delegar poderes tão amplos aos seus líderes. Por que eles abrem mão do poder de intervir no processo legislativo? Por que abdicam do poder de propor emendas? Por que reduzem o poder das comissões de controlar a agenda legislativa se é nelas que as oportunidades de participação são maiores?

As próximas seções oferecem uma resposta a estas perguntas, desenvolvendo a idéia de que o sistema político brasileiro passou por uma mudança fundamental de um período para o outro, cuja expressão conceitual mais apropriada é transição do sistema presidencialista faccional para o sistema presidencialista de coalizão racionalizado. Existe aqui uma referência intencional ao estudo de John Huber (1996), que empregou a noção de parlamento racionalizado para explicar por que a adoção de normas restritivas para a aprovação de legislação relevante conferiu previsibilidade e coerência à atividade parlamentar na Quinta República francesa, em comparação com o que havia ocorrido na Quarta República. A principal razão da adoção dessas normas, na visão de Huber, foi superar os problemas de coordenação endógenos a bancadas majoritárias, envolvendo a implementação sistemática de políticas de interesse nacional mediante a delegação de poderes decisórios ao Executivo.

Adotando uma linha semelhante, este artigo sustentará que a transferência de poderes decisórios ao Executivo, que começou no Brasil com o golpe de 1964 e foi posteriormente ratificada pela Constituição de 1988 (ver Pessanha, 1997), cria um forte estímulo para a organização dos deputados federais em partidos parlamentares - o que, por sua vez, aumenta a disciplina e a previsibilidade dos legisladores em plenário vis-à-vis o que normalmente ocorria antes de 1964. Esses temas serão discutidos na segunda e terceira seções. Além disso, a racionalização do Legislativo brasileiro influiu em outras importantes dimensões de suas atividades cotidianas, especialmente na estratégia de nomeação de membros para as comissões - este é o tema da quarta seção. A quinta seção conclui com alguns comentários sobre o impac- 
to do sistema racionalizado no tipo de democracia que estamos construindo no Brasil.

\section{O PODER DE CRIAR DESPESAS E O SEGREDO DA EFICIÊNCIA BRASILEIRA}

Figueiredo e Limongi chegaram muito perto de uma resposta às perguntas aludidas na introdução quando afirmaram que:

"Em suas relações com o Executivo, os representantes, considerados individualmente, se defrontam com problemas de coordenação. A melhor estratégia para cada um deles depende da ação adotada pelo resto dos membros do Legislativo. Suponhamos que um grande número de representantes que fazem parte da base de sustentação do governo faz uma ameaça de abandonar essa base se suas demandas particularistas não forem atendidas. Suponhamos que o governo perde a maioria do Legislativo se o grupo inteiro cumpre a ameaça. Imagine-se que o governo anuncia que não vai aceitar as exigências dos congressistas e ameaça os indisciplinados com a demissão de seus afilhados em cargos executivos. A fim de decidir como vai votar, cada congressista tem de estar informado sobre como se comportará o resto do grupo. O representante somente cumprirá sua ameaça se souber que determinado número de membros do grupo vai fazer o mesmo, um número suficientemente grande para impor uma derrota ao governo.

Do contrário, a ameaça não é acreditável. Suponha-se que um número de membros $x$ mantém a ameaça, mas um número $y$ de parlamentares que não cooperou é grande o suficiente para assegurar a vitória do governo. Ora, o governo é perfeitamente capaz de cumprir sua ameaça, porque sabe que é possível dispensar o apoio desse grupo de parlamentares e manter o apoio de uma maioria. Daí que as ameaças individuais são arriscadas e não podem ser cumpridas. Diante de um governo decidido, uma ameaça individual não é acreditável e durante o tempo em que for uma ameaça individual não há motivo algum para o governo mudar de estratégia (não atender às demandas de benefícios particularistas)" (1999:34).

A análise pode ser considerada quase perfeita. Entretanto, sustento que faltam ao argumento três elos teóricos fundamentais e inter-relacionados: primeiro, é necessário declarar explicitamente em que condições o presidente detém poder de barganha assimétrico diante de 
legisladores individuais. Segundo, é igualmente indispensável declarar qual o papel dos partidos parlamentares nessa barganha assimétrica. E, terceiro, se é verdade que o presidente tem enorme vantagem quando trata com legisladores individuais, então por que negociar com partidos, uma entidade coletiva? Tratarei de cada um desses elos teóricos em separado.

Quanto ao primeiro, é importante ressaltar que o poder de barganha do presidente somente se torna assimétrico quando os legisladores não têm fontes alternativas para a distribuição dos benefícios que desejam para seus redutos eleitorais. Nesse sentido, é fundamental lembrar a experiência de 1946-64 quando o Legislativo possuía considerável poder sobre o orçamento.

Assim como hoje, o Executivo tinha a prerrogativa constitucional de iniciativa da lei orçamentária. Entretanto, ao contrário do que ocorre atualmente, os legisladores podiam evitar, recorrendo a vários instrumentos procedimentais, a manipulação dos prazos por parte do presidente para impor suas preferências ao Congresso. Normas internas da Câmara referentes à definição das responsabilidades das comissões permanentes estabeleciam que a Comissão de Finanças podia encaminhar ao plenário uma proposta de orçamento quando o Executivo não o fizesse no prazo determinado pela Constituição. Isso significa que o ponto de reversão, nos casos em que o orçamento não era votado no prazo devido, não era tão favorável ao presidente quanto depois de aprovada a Constituição de $1988^{4}$. Se o presidente tentasse usar estrategicamente sua prerrogativa de iniciativa da lei orçamentária, por exemplo, demorando a encaminhar o projeto e com isso induzindo a uma decisão muito afastada do ponto ideal do legislador mediano, este teria a opção de recorrer à Comissão de Finanças e propor um pacote orçamentário distante do ponto ideal do presidente. Além do mais, durante o regime de 1946-64, os legisladores mantinham considerável poder de criação de despesas. Segundo a Constituição de 1946, artigo 75, capítulo relativo à capacidade de criar despesas dos congressistas:

\footnotetext{
"A lei de orçamento não conterá dispositivo estranho à previsão da receita e à fixação da despesa para os serviços anteriormente criados. Não se incluem nessa proibição:

I - a autorização para abertura de créditos suplementares e operações de crédito por antecipação da receita;
} 
II - a aplicação do saldo e o modo de cobrir o déficit" (Campanhole e Campanhole, 1986:228-229).

A mensagem é bem clara. Os legisladores estavam autorizados a interpretar as demandas locais e a atendê-las mediante recursos orçamentários, por meio de operações de crédito com antecipação da receita ou pela aplicação de saldos. O ponto relevante é que a autorização constitucional para tomar a iniciativa de políticas distributivas provoca um significativo impacto na produção legislativa da Câmara: $75,2 \%$ dos projetos aprovados propostos pelos legisladores referem-se a assuntos econômicos e administrativos (Figueiredo, 2000). Ademais, conforme demonstrei em outro trabalho (Santos, 1995), entre 1959 e 1963 mais de 50\% da produção endógena da Câmara destinava algum tipo de recurso público a localidades, indivíduos e grupos. Portanto, a magnitude do poder de barganha do presidente, relativamente à distribuição de patronagem, é uma função negativa da presença de fontes alternativas para a distribuição de bens divisíveis em benefício dos redutos eleitorais dos legisladores. Durante o regime de 1946-64, a lei do orçamento proporcionava uma dessas fontes, de modo que os deputados não ficavam tão dependentes do Executivo para promover suas carreiras políticas.

Quanto ao segundo elo teórico, o ponto crucial é entender como os partidos no Congresso podem contribuir para a realização dos objetivos políticos dos representantes. Relembremos o exemplo hipotético formulado por Figueiredo e Limongi: o presidente podia muito bem dispensar o apoio de vários parlamentares e, ainda assim, assegurar uma maioria favorável às suas proposições de políticas públicas. Ora, se a patronagem é, por definição, um recurso escasso, sua distribuição gera um custo para o presidente, isto é, para ele é racional minimizar a quantidade de patronagem distribuída. Assim, se o presidente é um monopolista de facto, e se é racional para ele minimizar a quantidade de patronagem distribuída, não há nenhuma garantia de que ele irá cumprir sua promessa na troca de votos por patronagem, pelo menos quando não existe nenhuma ameaça crível da parte dos legisladores. Em outras palavras, se falta credibilidade à ameaça individual de um deputado, e se para o presidente é racional economizar a distribuição de recursos de patronagem, ele terá um forte motivo para trapacear e não cumprir sua parte no trato com os legisladores. 
O presidente somente acreditará na veracidade de uma retaliação quando o grupo que está decidido a abandonar sua base de apoio for numeroso e seu comportamento minimamente disciplinado. Portanto, a estabilidade dos acordos entre o presidente e os legisladores, no sentido de que estes últimos se sintam seguros de que irão receber a patronagem reivindicada como parte da barganha, dependerá da capacidade dos congressistas para superarem os problemas de ação coletiva e se conduzirem como uma entidade coletiva vis-à-vis o presidente. O papel de um partido no Congresso é exatamente este, isto é, funcionar como uma entidade coletiva. Nesse sentido, os legisladores brasileiros fazem um investimento comum no valor da legenda do seu partido. Quanto mais homogêneas são as posições sobre as várias questões políticas, maior é o poder de barganha de cada membro individualmente. Assim sendo, o comportamento coeso em uma legenda comum é do interesse de cada deputado como forma de conferir credibilidade a uma ameaça que, do contrário, não chegará a importunar ator político tão poderoso quanto o presidente brasileiro.

É importante notar que, na falta desse incentivo, não haveria motivo algum para os deputados - que já são vítimas de um presidente monopolista - delegarem tantos poderes aos seus líderes na Câmara. Para ilustrar esse argumento, vejamos o Quadro 1, no qual se compara o controle dos líderes partidários sobre a pauta legislativa durante os dois períodos democráticos examinados neste artigo.

Quadro 1

Controle da Pauta de Votações pelas Lideranças Partidárias 1946-64 e Pós-88

\begin{tabular}{|l|c|c|}
\hline & 1946-64 & Pós-88 \\
\hline Colégio de Líderes & Não & Sim \\
Controle de Emendas em Plenário & Não & Sim \\
Encaminhamento de Voto & Não & Sim \\
\hline
\end{tabular}

Fonte: Câmara dos Deputados $(1955 ; 1994)$.

Três instituições fundamentais responsáveis pela organização do processo decisório na Câmara atualmente não existiam no período 1946-64. Primeiro, nesse período, não havia nenhuma instituição semelhante ao Colégio de Líderes, o que indica que os líderes de partidos não gozavam de muita influência na organização do calendário de votações da Câmara. O Colégio de Líderes foi criado em 1989 como 
organismo auxiliar da Mesa Diretora da Câmara para assuntos relacionados ao calendário de votações da Casa. Ele tem importância decisiva nos pedidos de urgência para a votação de projetos específicos, o que significa que as proposições devem ser votadas no prazo de 45 dias. O pedido de urgência é encaminhado à Mesa pelo Colégio de Líderes, e a assinatura de cada líder é ponderada pelo tamanho da bancada sob seu comando. Em seguida, o pedido é enviado ao plenário da Câmara para ser votado, o que pode ser feito por manifestação simbólica (Figueiredo e Limongi, 1995). Segundo, no período 1946-64, não havia condicionante algum à apresentação de emendas por legisladores individuais. No regime atual há restrições ao direito dos deputados de fazer emendas em plenário. Quando um projeto é submetido à votação em regime de urgência, as emendas não são consideradas, salvo se contam com a assinatura de pelo menos um décimo da Câmara ou dos líderes cujas bancadas representam esse número. Finalmente, no período pré-64, a prática de encaminhamento de voto pelos líderes era desconhecida.

Como entender a mudança de papel das lideranças partidárias na Câmara? Minha hipótese é que os partidos políticos são mais relevantes no período recente porque sua existência traz vantagens para os parlamentares em suas negociações com o Executivo. Organizados em partidos minimamente disciplinados, eles protegem-se da ação monopólica do presidente. Isso, por sua vez, garante o fluxo de projetos no plenário da Câmara e, em compensação, os legisladores recebem do Executivo benefícios de patronagem a ser distribuídos em seus redutos eleitorais. Nesse sentido, a adesão às proposições políticas do partido é um bem público para a bancada como um todo, e esse benefício somente pode ser alcançado se os parlamentares delegam aos líderes uma parte considerável de seu controle sobre a pauta legislativa com a finalidade de remover os problemas de coordenação.

Quanto ao terceiro elo teórico, é preciso considerar que há uma opinião consensual de que o presidente é o ator mais interessado na estabilidade do sistema político brasileiro. Por quê? Porque os presidentes são constitucionalmente responsáveis pela promoção de políticas públicas de alcance nacional, mas essas políticas só podem ser decretadas em um ambiente institucional minimamente estável. Além do mais, os chefes do Executivo são os únicos políticos eleitos por um eleitorado nacional e por isso têm incentivos eleitorais para levar a efeito políticas de impacto mais amplo. 
Existe, aqui, certamente, uma premissa omitida. Por que os presidentes procuram implementar um programa de amplo impacto? É plausível sugerir, como dito acima, que o chefe do Executivo age em resposta a um eleitorado nacional, mas se isso for verdade, teremos de incluir a premissa comportamental de que interessa ao presidente ser visto como um governante competente, capaz de garantir a implementação de um projeto coerente de desenvolvimento nacional. Nesse sentido, o presidente seria um "maximizador de agenda" - ele depende de um Congresso cooperativo para pôr em prática um conjunto de políticas públicas coerentes, na intenção de reeleger-se, de preparar uma volta ao cargo pelo menos por mais um mandato, ou de patrocinar a candidatura de um herdeiro político (Amorim Neto e Santos, 2001).

Estamos agora em condições de compreender, do ponto de vista do comportamento dos partidos parlamentares, a transição do modelo brasileiro de sistema presidencialista faccional para um sistema de coalizão racionalizado. Em primeiro lugar, temos os atores: "um presidente maximizador de agenda" e legisladores em busca de benefícios para seus redutos eleitorais. Em segundo, dois contextos institucionais diversos: o primeiro, que predominou durante o regime de 1946-64, caracterizou-se pela existência de fontes alternativas de distribuição de benefícios. Naquela conjuntura, as estratégias individualistas podiam ser eficazes em circunstâncias específicas, na medida em que entidades coletivas, como os partidos, não eram tão relevantes para seus membros individuais. O segundo contexto, que define o regime pós-88, caracteriza-se pelo monopólio do Executivo sobre a iniciativa em matéria orçamentária. É fácil imaginar que, nessas circunstâncias, os congressistas tenham interesse comum na consistência do comportamento de suas respectivas bancadas em plenário. Quando os legisladores estão organizados em partidos disciplinados, a força do seu apoio parlamentar aproxima-se do peso dos partidos que formalmente integram a coalizão governista. Isso, por sua vez, garante o fluxo da legislação no plenário da Câmara e, em contrapartida, os parlamentares são aquinhoados pelo Executivo com benefícios de patronagem que eles distribuem aos seus redutos eleitorais.

Acredito, portanto, que uma transferência muito específica de capacidades decisórias para o Poder Executivo, que no Brasil começou com o golpe militar de 1964 e foi ratificada pela Constituição de 1988, 
criou um forte incentivo à organização dos deputados federais em partidos parlamentares, resultando no aumento da disciplina e da previsibilidade do plenário em relação ao que ocorria antes de 1964. O controle do Executivo sobre a iniciativa em assuntos distributivos retirou um instrumento fundamental para que os congressistas mantivessem ou ampliassem sua influência política. Dado esse monopólio, a única fonte de distribuição de benefícios é o próprio Executivo, o que significa que o presidente ganha enorme poder de barganha vis-à-vis os legisladores individuais. Nesse caso, a cooperação com partidos parlamentares é a melhor estratégia para os parlamentares fortalecerem seu poder de barganha diante do chefe do Executivo. E isso explica por que, em oposição ao que ocorria no regime de 1946-64, o comportamento de um partido minimamente disciplinado é essencial para os atuais legisladores brasileiros.

Com isso se completa a transição de um sistema presidencialista faccional para um presidencialismo de coalizão racionalizado. Podemos compreender por que os presidentes conseguem formar sua base parlamentar de apoio sem tentar comprar a aquiescência dos membros dos partidos de oposição. Em comparação com a experiência de 1946-64, o comportamento dos partidos no plenário da Câmara é mais disciplinado e as coalizões formadas em torno de políticas públicas governamentais são mais coerentes e homogêneas. Daqui por diante, essa é nossa expectativa básica.

\section{RESULTADOS EMPÍRICOS SOBRE O COMPORTAMENTO DOS PARTIDOS NO PLENÁRIO DA CÂMARA}

Nesta seção investigo o padrão de relações entre Executivo e Legislativo durante os dois períodos em exame. Minha hipótese é que esse padrão difere essencialmente nos dois períodos. A partir da Constituição de 1988, coalizões de apoio ao presidente têm se formado em torno de uma estrutura partidária consistente, o que significa que o êxito do governo passou a depender do apoio partidário e não de alianças ad hoc construídas mediante a distribuição marginal de patronagem. Por conseguinte, os presidentes negociam com os partidos e não com cada congressista ou com facções partidárias. Em contraposição, durante o regime de 1946-64, as negociações individuais entre o presidente e membros dos partidos de oposição, em que o presidente buscava obter apoio parlamentar excedente, como um seguro contra o es- 
pectro de um comportamento indisciplinado de sua base formal, marcavam o padrão das relações Executivo-Legislativo.

Para testar o argumento quanto à distinção fundamental entre os dois períodos, construí um critério de relevância para examinar as votações nominais levando em conta fatos históricos, o que resultou na introdução de aspectos mais substantivos para a escolha de votações relevantes ${ }^{5}$. Sabe-se, por exemplo, que, no regime de 1946-64, a coalizão PSD/PTB dava respaldo parlamentar ao desenvolvimento das políticas dos governos Vargas (1951-54) e Kubitschek (1956-60). Contrapondo-se ao projeto de crescimento industrial brasileiro por substituição de importações, os líderes da UDN chamaram a atenção para os custos sociais envolvidos na proteção da indústria nacional e questionaram as ligações perigosas entre políticos, empresários e operários manuais. Portanto, uma forma adequada de definir a importância das votações nominais nesse período é considerar relevantes as votações relativas às proposições pertinentes ao projeto desenvolvimentista ${ }^{6}$.

Durante o primeiro mandato de Fernando Henrique Cardoso, o principal item do seu programa de governo consistiu em emendas à Constituição de 1988. De um lado, estavam os partidos que apoiavam o presidente na luta pela revisão do modelo de crescimento econômico por substituição de importações. Na visão dos líderes governistas, somente uma reforma profunda de vários artigos da Constituição poderia sustentar uma nova fase de desenvolvimento econômico e social no Brasil - esses partidos eram o PSDB, o PMDB, o PPB e o PTB. De outro lado, no campo da oposição, o PT e o PDT alegavam que as reformas propostas pelo governo representavam a submissão do país às determinações de organismos financeiros internacionais, como o FMI e o Banco Mundial. Assim, para o período pós-88, os critérios substantivos para a escolha de votações nominais relevantes levaram em consideração somente as votações relativas a emendas à Constituição de 1988 que tiveram lugar durante o primeiro mandato de Fernando Henrique Cardoso.

A análise de dados seguirá dois procedimentos: em primeiro lugar, examinarei as médias e desvios-padrão dos índices de Rice para os principais partidos, nos dois períodos, em votações nominais selecionadas; em segundo, estudarei as coalizões construídas em torno dessas votações. Vejamos primeiro as taxas de coesão. 
Tabela 1

Média e Desvio-Padrão dos Índices de Rice em Votações das Políticas Desenvolvimentistas

1951-1962

\begin{tabular}{l|c|c|c}
\hline & PSD & PTB & UDN \\
\hline Índice de Rice & $\begin{array}{c}0,63 \\
(0,30)\end{array}$ & $\begin{array}{c}0,64 \\
(0,27)\end{array}$ & $\begin{array}{c}0,57 \\
(0,30)\end{array}$ \\
\hline
\end{tabular}

Fonte: Diário do Congresso Nacional.

Tabela 2

Média e Desvio-Padrão dos Índices de Rice em

Votações da Reforma Constitucional

1995-1997

\begin{tabular}{l|c|c|c|c|c|c|c}
\hline & PPB & PDT & PFL & PMDB & PSDB & PT & PTB \\
\hline Índice de Rice & 0,72 & 0,90 & 0,92 & 0,68 & 0,89 & 0,98 & 0,84 \\
Desvio-Padrão & $(0,24)$ & $(0,15)$ & $(0,14)$ & $(0,20)$ & $(0,12)$ & $(0,10)$ & $(0,18)$ \\
\hline
\end{tabular}

Fontes: Banco de Dados Legislativos/CEBRAP; Nicolau (1999).

Como se pode verificar, há uma diferença significativa entre os dois regimes. O índice de coesão mais alto no primeiro período foi obtido pelo PTB $(0,64)$, enquanto no período recente foi alcançado pelo PT $(0,98)$. O PMDB obteve o escore mais baixo do pós- $88(0,68)$. No entanto, este foi superior ao valor mais alto do regime de 1946, apesar de não ser uma diferença significativa. Cabe notar que o desvio-padrão do primeiro período é sistematicamente superior ao do segundo, e isso indica que, relativamente a matérias de interesse crucial para o governo, o comportamento dos partidos durante o intervalo 1946-64 era significativamente menos previsível do que depois de 1988. As tabelas abaixo mostram uma outra forma de observar esses fenômenos.

Tabela 3

Coalizões em Plenário Relacionadas com Políticas Desenvolvimentistas 1951-1962

\begin{tabular}{l|c|c|c|c}
\hline Coalizões & Sim & Não & Número & \% \\
\hline Unanimidade & 14 & 12 & 26 & 57,8 \\
PSD/PTB & 4 & 5 & 9 & 20,0 \\
PSD/UDN & 1 & 1 & 2 & 4,4 \\
UDN/PTB & 5 & 3 & 8 & 17,8 \\
Sem Conflito & - & - & - & - \\
\hline Total & $\mathbf{2 4}$ & $\mathbf{2 1}$ & $\mathbf{4 5}$ & $\mathbf{1 0 0 , 0}$ \\
\hline
\end{tabular}

Fontes: Diário do Congresso Nacional; Lafer (1970). 
Tabela 4

Coalizões em Plenário Relacionadas com Políticas Reformistas 1995-1997

\begin{tabular}{l|c|c|c|c}
\hline Coalizões & Sim & Não & Número & $\%$ \\
\hline Unanimidade & 14 & 8 & 22 & 11,3 \\
PDT/PFL/PMDB/PSDB/PPB & 1 & 1 & 2 & 1,0 \\
PDT/PFL/PMDB/PSDB/PT/PTB & 0 & 2 & 2 & 1,0 \\
PDT/PFL/PMDB/PSDB/PTB/PP & 6 & 1 & 7 & 3,6 \\
PDT/PFL/PSDB/PT & 0 & 1 & 1 & 0,5 \\
PDT/PFL/PSDB/PT/PTB & 1 & 0 & 1 & 0,5 \\
PFL/PMDB/PSDB/PTB & 1 & 2 & 3 & 1,5 \\
PFL/PMDB/PSDB/PTB/PPB & 84 & 70 & 154 & 79,4 \\
PFL/PMDB/PTB/PPB & 0 & 1 & 1 & 0,5 \\
PFL/PSDB/PTB/PPB & 0 & 1 & 1 & 0,5 \\
\hline Total & $\mathbf{1 0 7}$ & $\mathbf{8 7}$ & $\mathbf{1 9 4}$ & $\mathbf{1 0 0 , 0}$ \\
\hline
\end{tabular}

Fontes: Banco de Dados Legislativos/CEBraP; Nicolau (1999).

Nessas tabelas, votações unânimes são definidas como aquelas em que maiorias dentro das bancadas dos principais partidos votaram da mesma maneira. As fileiras em que aparecem dois ou mais partidos correspondem a votações nominais em que uma maioria dentro dos mesmos partidos votou da mesma maneira e saiu vitoriosa. Pode-se verificar, portanto, quais coalizões foram construídas para decidir questões cruciais para o governo.

Observa-se, novamente, significativa diferença entre os dois períodos: durante o regime de 1946-64, em 57,8\% das votações nominais houve aglutinação de maiorias dentro dos três principais partidos que propiciaram vitórias ao governo - isso significa que o modelo de substituição de importações tinha o apoio de facções majoritárias no interior de cada um desses grandes partidos e não de partidos disciplinados que votavam como um bloco unido. Nesse sentido, nada poderia estar mais distante das reformas de mercado conduzidas durante o primeiro mandato de Fernando Henrique Cardoso: em 79,4\% das votações nominais, PFL, PMDB, PSDB, PTB e PPB uniram-se para derrotar o PT e o PDT e mudar a Constituição de 1988. Se acrescentarmos a esse quadro os escores de coesão partidária nos dois períodos, o cenário é ainda mais convincente: durante o regime de 1946, a imple- 
mentação de políticas desenvolvimentistas dependeu da adesão de maiorias no interior de cada um dos principais partidos, porque o comportamento das bancadas desses partidos era relativamente imprevisível. Isso, por outro lado, levou o chefe do Executivo a buscar no partido de oposição, a UDN, os votos necessários à execução de suas políticas. No período pós-88, os partidos que formalmente integravam a base de apoio do governo eram os mesmos que decidiam as votações favoravelmente às propostas do presidente no plenário da Câmara, e isso é igual a dizer que não havia razão alguma para o presidente se empenhar em obter apoio ad hoc dos partidos de oposição. De fato, esses resultados confirmam minha expectativa teórica.

\section{AS ESTRATÉGIAS DOS PARTIDOS PARA A NOMEAÇÃO DE MEMBROS PARA AS COMISSÕES}

O objetivo desta seção é estudar o impacto do presidencialismo de coalizão racionalizado na política de indicações de membros para duas comissões decisivas - a Comissão de Constituição e Justiça e a Comissão de Finanças e Tributação - dos dois maiores partidos brasileiros, o PSD, no período 1946-64, e o PMDB, no pós-887. Antes de promover os testes empíricos pertinentes, vale a pena nos determos em breve digressão teórica.

A escolha de parlamentares para integrar as comissões está centralizada nas mãos dos líderes partidários. A rigor, as normas vigentes determinam que as designações sejam feitas pela Mesa Diretora, ouvidos os líderes dos partidos ${ }^{8}$. A conseqüência mais importante dessa regra é que as nomeações para as comissões são basicamente uma tarefa do líder. Em suma, analisar as nomeações para as comissões no Brasil significa estudar a decisão de um agente específico, o líder do partido.

Além disso, é importante notar que as comissões se distinguem por sua competência. De acordo com Cox e McCubbins (1993), comissões de competência estreita são aquelas cujas decisões não afetam outros membros do partido; as de competência ampla são aquelas cujas decisões causam impacto na imagem pública do mesmo. Uma legislação de alcance nacional, por exemplo, poderia melhorar a imagem coletiva dos membros do partido. Algumas comissões - a de Constituição e Justiça e a de Finanças e Tributação, por exemplo - têm sempre o direito de opinar nesse tipo de legislação. À primeira cabe analisar a cons- 
titucionalidade de um projeto de lei apresentado, e à segunda avaliar qualquer proposição que tenha impacto fiscal. As competências também se distinguem pelas que têm baixa e alta externalidade (idem). Um bom exemplo da última é quando um membro do partido pode ser afetado particularmente pelas decisões da comissão. Se uma comissão, digamos, a CCJ, tem poder de veto sobre qualquer proposição encaminhada à Câmara, os efeitos das decisões tomadas por ela influenciam na probabilidade de aprovação de projetos de lei apresentados pelos parlamentares sem assento nessa comissão. A CFT é outro exemplo de comissão com alta externalidade e sua finalidade é informar a Câmara sobre qualquer proposição que tenha impacto fiscal. Dessa maneira, as políticas distributivas propostas por parlamentares que não são membros da CFT devem ser aprovadas por membros dessa comissão.

Um último ponto teórico diz respeito às duas ordens de fatores levadas em consideração pelos líderes partidários ao escolherem os membros para compor as comissões mencionadas: lealdade partidária e expertise. Tratemos primeiro desta última variável. Os líderes não se preocupam exclusivamente com a questão do comportamento politicamente leal porque também têm de se ocupar com a qualidade das informações contidas nos projetos examinados pela comissão. Cabe lembrar, a esse respeito, que na Câmara brasileira a reeleição não é uma prioridade para os deputados (Samuels, 1998; Santos, 2000). Abandonada a hipótese do interesse prioritário na reeleição, manifesta-se um padrão muito instável de nomeações para as comissões, que faz com que seus integrantes não desenvolvam conhecimentos especializados durante seus mandatos. Conseqüentemente, expertise prévia sobre políticas específicas é uma variável decisiva nos cálculos dos legisladores na hora de fazer indicações para as comissões. Em outras palavras, é preciso considerar que as preocupações dos líderes com a lealdade política são balanceadas pela necessidade de conhecimentos especializados nas políticas públicas.

A melhor estratégia para aferir o grau de especialização prévia de um deputado em determinada matéria é atentar para sua experiência profissional. Quando não há na bancada profissionais bem informados nos temas relacionados com a atividade da comissão, os líderes vão procurar proxies em experiências profissionais prévias. Estas proxies podem ser o exercício de cargos executivos anteriores, eletivos ou não. É importante mencionar que, neste particular, a prevalência de 
um sistema racionalizado não significa que os líderes sofram atualmente menos restrições do que na época em que vigorava uma lógica faccional. Portanto, suponho que a variável "especialização" tenha impacto significativo nas nomeações tanto no período de 1946-64 quanto no pós-88.

Consideremos agora a variável lealdade partidária. Na fase faccional, o membro de uma comissão tenderá a destacar o conteúdo partidário da legislação proposta se estiver minimamente comprometido com a facção majoritária do seu partido. Como o líder estima a lealdade do parlamentar com sua legenda? No caso brasileiro, a decisão do líder está relacionada com o comportamento do membro da comissão durante votações cruciais em plenário. Nesse sentido, minha hipótese é que os líderes verificam o grau de compromisso de um deputado pelo seu comportamento manifesto. Quanto mais esse deputado vota com a maioria do seu partido, maior é o seu compromisso com a facção majoritária da legenda, e maior, portanto, a confiança política inspirada por esse membro no líder partidário. No período pós-88, entretanto, a liberdade de escolha dos líderes não é limitada pelas facções partidárias, pelo simples fato de estas não serem mais politicamente relevantes no que tange ao comportamento em plenário, o que explica sua atenção estar voltada basicamente para a aptidão de um parlamentar para produzir políticas públicas bem fundamentadas. Em resumo: no período 1946-64, os líderes combinavam o critério de lealdade partidária com os conhecimentos especializados nas políticas, estipulando um grau mínimo de lealdade partidária - a ser calculado pela taxa média de lealdade partidária da sua bancada - para que um especialista fosse nomeado para uma comissão importante. No período pós-88, somente o critério de especialização representaria uma restrição à tarefa do líder.

Estamos agora em condições de formalizar nossas proposições empíricas referentes às nomeações dos partidos para comissões de controle:

1. O coeficiente de experiência profissional deve ser positivo e significativamente diferente de zero.

2. Se o coeficiente de experiência profissional não for significativo, pelo menos um dos coeficientes substitutivos de especialização prévia, ou seja, ter sido membro do Executivo, deve ser positivo e significativamente diferente de zero. 
3. O coeficiente de lealdade partidária não deve ser significativamente diferente de zero para o Congresso de 1991-1998.

\section{Operacionalização das Variáveis e Teste de Hipóteses}

Para testar essas hipóteses, utilizei um modelo logit multivariado. A variável dependente - pertencer a uma das duas comissões de controle-é operacionalizada pela atribuição do valor 0 se o deputado nunca ocupou uma vaga na comissão, e 1, no caso oposto. Os dados sobre participação em comissões foram colhidos no Diário do Congresso. As variáveis independentes são as seguintes:

Especialização prévia dos membros da comissão - essa variável tem dois componentes: o primeiro refere-se à experiência profissional do membro da comissão ou sua atividade econômica principal antes de se tornar deputado. Os dados relativos a este componente foram extraídos do Repertório Biográfico dos Deputados Brasileiros, geralmente publicado no início de cada legislatura, poucos meses antes da primeira sessão (Deputados Brasileiros: 1826-1976; Fleischer, 1981) ${ }^{9}$. Duas variáveis dummies foram construídas para dar conta da especialização anterior nas áreas de políticas cobertas pelas comissões de controle:

a) Advogados: recebe o valor 1 quando o deputado é formado em Direito; caso contrário, recebe o valor 0 .

b) Especialistas em economia e assuntos financeiros: recebe o valor 1 para todos os deputados formados em economia, administração ou ciências contábeis ou para todos os que atuavam nesse ramo como principal atividade econômica anterior; zero, do contrário.

O segundo componente da variável diz respeito à atividade política anterior dos membros da comissão, o que pode indicar uma formação prévia em políticas públicas. Conforme já mencionei, quatro variáveis foram utilizadas em substituição à especialização anterior:

a) Exercício de cargos eletivos no Poder Executivo: toma o valor 1 se um deputado foi prefeito ou governador; 0 , em caso contrário. Os dados sobre essa variável também foram colhidos no Repertório Biográfico (Deputados Brasileiros: 1826-1976; Fleischer, 1981).

b) Exercício de cargos não eletivos no Poder Executivo: recebe o valor 1 se um deputado exerceu anteriormente uma função não eletiva no 
Poder Executivo nos níveis local, estadual ou federal, e 0, em caso contrário. Os dados foram colhidos no Repertório Biográfico.

c) Taxa de lealdade partidária ${ }^{10}$ : essa variável mostra a porcentagem anual de votações nominais importantes em que um deputado votou com a maioria da bancada do seu partido multiplicada pelo comparecimento do parlamentar a essas votações.

d) Desempenho eleitoral do deputado: essa variável mostra o número de cotas eleitorais do deputado. Obtém-se esse número dividindo o total de votos no nome do deputado pela cota eleitoral do distrito. Em outras palavras, a variável explicita se o parlamentar se sente independente do desempenho eleitoral de outros candidatos no mesmo distrito. Dados para essa variável foram coletados de $D a$ dos Estatísticos do TSE.

São essas as variáveis por mim utilizadas para testar o modelo de nomeação para comissões no presidencialismo de coalizão. Testarei igualmente as hipóteses baseadas na idéia de incentivos eleitorais. Por esse motivo, incluí nos modelos uma variável que indica o desempenho eleitoral no distrito do membro da comissão. Um modelo baseado em incentivos eleitorais supõe que os coeficientes dessa variável sejam positivos e significativamente diferentes de zero. O modelo defendido neste trabalho não supõe nem que seus coeficientes sejam positivos nem significativamente diferentes de zero.

O primeiro grupo de modelos calcula os coeficientes logit para as decisões de nomeação de membros para comissões nas Câmaras de 1951-1962. Veja a Tabela $5^{11}$.

O primeiro modelo é um modelo logit de máxima verossimilhança das nomeações do PSD para a CCJ. De modo coerente com o modelo de nomeações para comissões, o coeficiente de especialização anterior é positivo e significativo. O efeito da lealdade partidária também é positivo e significativo, confirmando a expectativa teórica. Por outro lado, se o impacto do desempenho eleitoral é positivo, isto não é significativo, o que, novamente, confirma a previsão do modelo. O segundo modelo relaciona-se com as nomeações do PSD para a CFT. O coeficiente de experiência profissional é positivo, mas não significativo. Mas o efeito da variável prefeito (eleito) ou exercício de um cargo não eletivo no Executivo estadual é positivo e significativo, o que confirma a expectativa do meu modelo. Conforme assinalei, o modelo 
Tabela 5

Regressão Logit Multivariada:

Nomeações do PSD para a CCJ e a CFT

\begin{tabular}{l|c|c}
\hline \multirow{2}{*}{ Variáveis Independentes } & $\mathbf{1}$ & $\mathbf{2}$ \\
\cline { 2 - 3 } & CCJ & CFT \\
\hline Desempenho eleitoral & 0,00 & $-0,00$ \\
Experiência profissional & $(9,23 \mathrm{e}-06)$ & $(0,00)$ \\
& $1,64^{*}$ & 0,94 \\
Taxa de lealdade partidária & $(0,31)$ & $(0,65)$ \\
& $0,91^{* * *}$ & $1,10^{* *}$ \\
Prefeito & $(0,53)$ & $(0,50)$ \\
Governador & - & $0,72^{*}$ \\
Cargo no Executivo local & - & $(0,20)$ \\
Cargo no Executivo estadual & - & $-1,29^{* * *}$ \\
Cargo no Executivo federal & - & $(0,73)$ \\
Qui-quadrado & - & - \\
N & -143 & $0,82^{*}$ \\
\hline
\end{tabular}

* Significante ao nível de 0,01.

** Significante ao nível de 0,05 .

*** Significante ao nível de 0,1.

prediz que, quando não há disponibilidade de pessoas com experiência profissional, os líderes partidários usam substitutos com especialização prévia. Ter feito parte do Executivo é um desses substitutos. O efeito da lealdade partidária é positivo e significativo, o que também confirma o modelo. Além disso, o impacto do desempenho eleitoral é negativo, embora não significativo.

O segundo grupo de modelos estima os coeficientes logit das nomeações do PMDB para comissões da Câmara dos Deputados durante o período 1991-98. Os resultados estão na Tabela 6. 
Tabela 6

Regressão Logit Multivariada:

Nomeações do PMDB para a CCJ e a CFT

\begin{tabular}{l|c|c}
\hline \multirow{2}{*}{ Variáveis Independentes } & $\mathbf{1}$ & $\mathbf{2}$ \\
\cline { 2 - 3 } Desempenho eleitoral & CCJ & CFT \\
\hline \multirow{2}{*}{ Experiência profissional } & $-1,80 \mathrm{e}-06$ & $0,00^{* *}$ \\
& $(4,96 \mathrm{e}-06)$ & $(4,84 \mathrm{e}-06)$ \\
Taxa de lealdade partidária & $3,02^{*}$ & $2,1^{*}$ \\
& $(0,43)$ & $(0,43)$ \\
Prefeito & $-0,15$ & $-0,66$ \\
& $(0,61)$ & $(0,69)$ \\
Governador & - & $-0,60$ \\
& - & $(0,47)$ \\
Cargo no Executivo local & - & $-0,80$ \\
& - & $(0,81)$ \\
Cargo no Executivo estadual & $-0,50$ \\
Cargo no Executivo federal & - & $(0,52)$ \\
Qui-quadrado & 65,76 & 0,09 \\
$\mathrm{~N}$ & & $(0,36)$ \\
\hline
\end{tabular}

* Significante ao nível de 0,01 .

** Significante ao nível de 0,05.

O primeiro modelo é um modelo logit de máxima verossimilhança das nomeações do PMDB para a CCJ. Confirmando meu modelo de nomeações de membros para as comissões, o coeficiente de especialização prévia é positivo e significativo. No entanto, o efeito da lealdade partidária é negativo e não significativo, o que é compatível com o modelo de presidencialismo de coalizão racionalizado. $\mathrm{O}$ segundo modelo trata das nomeações do PMDB para a CFT. O coeficiente de experiência profissional é positivo e significativo. Esses resultados confirmam a expectativa do modelo, principalmente se nos lembrarmos de que não há nenhum impacto relevante de antigos membros eleitos e não eleitos para cargos no Poder Executivo sobre a variável dependente. O efeito da lealdade partidária é negativo e não significativo, o que também confirma a expectativa, e o impacto do desempenho eleitoral é positivo e significativo, confirmando o modelo da auto-seleção. 
Que lições poderiam ser tiradas desses resultados? O quadro geral das descobertas indica que a direção da pesquisa está basicamente correta - o modelo de nomeações para comissões foi corroborado pelos testes realizados. Seus parâmetros são, sem dúvida, os que melhor predizem as decisões de nomeações. A especialização anterior está sempre associada de forma positiva e significativa ao fato de integrar as comissões de controle. A taxa de lealdade partidária também se associa positiva e significativamente a essa variável dependente, mas somente no regime de 1946-64, o que confirma o modelo racionalizado de presidencialismo de coalizão. É interessante notar que nos casos de impacto da baixa lealdade partidária, o efeito da especialização anterior é significativo ao nível de 0,01 , indicando que os líderes de partido sofriam grandes restrições por causa da barreira da expertise ao ingresso nas comissões. Pode-se concluir, portanto, que o comportamento partidário e a posse de conhecimentos especializados interagem quando os líderes decidem sobre as nomeações. Em outras palavras, as estimativas das equações mostram que em um modelo faccional os líderes combinam os critérios de lealdade partidária e a qualidade de especialistas em políticas públicas, estipulando um grau mínimo de lealdade para um parlamentar ser indicado para uma comissão muito importante, ao passo que no modelo racionalizado apenas a qualidade de especialista apareceu como determinante.

\section{CONCLUSÃO}

A principal contribuição deste artigo é mostrar que a atual dinâmica legislativa no Brasil deve ser estudada levando em consideração a experiência do período 1946-64. A partir de tal comparação, e mediante a utilização dos conceitos de presidencialismo de coalizão faccionalizado e racionalizado, compreendem-se os mecanismos cruciais que explicam um comportamento legislativo mais previsível hoje em dia do que aquele que seria de se esperar quando somente são levados em conta incentivos vinculados à conexão eleitoral e ao sistema de governo. De fato, os estudos de Figueiredo e Limongi (1999) já haviam demonstrado a relevância dos procedimentos decisórios internos ao Congresso Nacional e também dos poderes constitucionais em mãos do Executivo para o entendimento do modo pelo qual se dá a interação do presidente com o Poder Legislativo e, no interior deste, entre os líderes e as bancadas partidárias. O presente artigo procurou avan- 
çar nesse entendimento, identificando exatamente o mecanismo causal responsável pela associação entre ampliação dos poderes presidenciais e alteração do comportamento partidário na Câmara dos Deputados. Vem daía importância da comparação com o regime pré-64.

Os resultados foram bastante expressivos: o padrão de coalizão em torno da agenda presidencial foi significativamente diverso nos dois períodos. No primeiro, partidos divididos, coalizões amplas envolvendo parcelas relevantes de partidos oposicionistas. No segundo, um padrão consistente de governo versus oposição, com razoável disciplina entre os diversos parceiros do governo e alta disciplina por parte da oposição. No âmbito da relação entre líderes e bancadas, percebeu-se diferença igualmente importante no que se refere à política de nomeações para as principais comissões da Câmara. No período 1946-64, a lógica das facções levava os líderes a um cuidadoso escrutínio do comportamento mais ou menos leal do membro para com a parcela majoritária do partido. No período pós-88, apenas a restrição relativa à especialização prévia do membro apareceu como determinante.

Qual o aprendizado mais geral a ser extraído do texto? Essencialmente, pode-se dizer que a mudança na capacidade alocativa do Congresso foi decisiva para a "racionalização" do comportamento legislativo. Com isto não quero dizer que a ampliação dos poderes orçamentários do presidente foi benéfica. O ponto não é normativo, mas tento detectar os mecanismos que têm caracterizado nosso processo democráti$\mathrm{co}$, mais precisamente no que tange ao relacionamento entre partidos, Legislativo e presidente. Nesse aspecto, é fato que atualmente encontramos um padrão mais consistente de comportamento partidário. Se isto contribui para o aprofundamento da democracia, é uma questão de inclinação de cada um. Se reduz a taxa de clientelismo e aumenta a consistência das políticas públicas, não foi intenção do texto medir. Se melhora a vida do eleitor no sentido de identificar de forma mais eficiente diferenças entre os partidos, só o tempo dirá. Uma certeza existe, no entanto: reduz-se substancialmente o poder de barganha de parlamentares tomados individualmente e com isso os incentivos para que políticos com aspirações mais ambiciosas permaneçam mais tempo atuando no Legislativo (ver Santos, 2000). 


\section{NOTAS}

1. O estudo mais importante sobre o assunto é de Abranches (1988).

2. Para uma posição intermediária, ver Nicolau (2000).

3. As exceções são Amorim Neto (1994; 1998), Figueiredo (2000) e Santos (1997).

4. De acordo com o artigo X da Constituição de 1988, se o Congresso não aprovar o orçamento no prazo determinado, o Executivo está automaticamente autorizado a fazer despesas, conforme previsto no orçamento, em uma base mensal.

5. Em outro contexto, mostrei que, de modo geral, as taxas de disciplina dos partidos brasileiros durante o período 1946-64 eram significativamente menores do que as que verificamos no período recente (ver Santos, 1997).

6. Sobre as relações entre Executivo e Legislativo referentes ao projeto desenvolvimentista, ver Carvalho (1977), Lafer (1970) e Santos (1986). As votações nominais relativas a esse projeto foram extraídas de Lafer (1970).

7. Para um bom estudo sobre a questão das nomeações para comissões no Brasil pós-88, ver Pereira e Mueller (2000). A diferença entre esse trabalho e a abordagem que estou propondo nesta seção é de três ordens: primeira, minha análise compara duas experiências democráticas, enquanto Pereira e Mueller limitam sua investigação ao período pós-88; segunda, a intenção desses autores era detectar a influência do Poder Executivo no processo, enquanto meu objetivo é observar mudanças nos padrões de critérios partidários para a escolha de membros para comissões muito importantes; e, por último, eles estudaram todas as comissões, inclusive as especiais. Como será visto, limitei minha pesquisa a duas comissões de controle, a CCJ e a CFT.

8. Em outras palavras, não existe um comitê do comitê, como na Câmara de Representantes dos Estados Unidos (ver Câmara dos Deputados, 1955:99; 1994:61).

9. As informações contidas no Repertório são fruto de entrevistas. Os dados foram reunidos em duas etapas: primeiramente, foram registradas e codificadas todas as profissões e atividades econômicas. Observou-se, porém, que os dados não representavam adequadamente a atividade econômica de um deputado. Em outros termos, o Repertório contém "excesso" de informações sobre as profissões declaradas por exemplo, há uma elevada incidência de professores e jornalistas, embora isto não seja relevante na biografia de um deputado. Outro aspecto diz respeito à informação sobre a experiência acadêmica de um legislador, o que não indica necessariamente sua atividade econômica - é o caso dos advogados, engenheiros, contabilistas etc. que não exercem essas profissões, mas fizeram questão de declará-las. Em segundo lugar, para resolver esse problema, refiz a codificação das profissões de modo a separar a experiência acadêmica dos dados sobre atividades econômicas regulares. Note-se que "experiência acadêmica" é um dado preciso e confiável, mas o mesmo não acontece com "atividade econômica", que depende de informações dadas pelo parlamentar. Isto explica o fato de a principal dificuldade ter sido identificar e eliminar as "atividades econômicas" não representativas da carreira de um deputado. Portanto, na revisão dessas informações, não foram levadas em conta ocupações não exercidas de modo contínuo. Da mesma forma, as atividades, mesmo quando realizadas durante as eleições, foram consideradas não relevantes 


\section{Fabiano Santos}

se acompanhadas por outras que geralmente exigem mais atenção, tais como a propriedade rural ou de empresas. Assim, quando um deputado foi jornalista ou professor no começo de sua carreira, mas se formou e trabalhou como engenheiro, por exemplo, e na época das eleições exercia funções empresariais, ele foi classificado como formado em engenharia mas atuando como empresário, ao passo que, originalmente, ele tinha sido identificado como professor, jornalista, engenheiro e empresário.

10. O indicador de lealdade partidária será obtido indutivamente, ou seja, a partir das preferências reveladas pelos deputados em plenário. Em primeiro lugar, examina-se o comportamento da maioria da bancada de um partido diante de votações nominais importantes. Em seguida, assinala-se o valor 1 (um) para um deputado cada vez que seu voto seguir a decisão da maioria de seu partido, e 0 (zero) nos casos em que seu voto difere desta. Finalmente, divide-se o valor obtido para o deputado pela quantidade de vezes em que este esteve presente nessas votações relevantes. O critério para a saliência de votações nominais foi extraído do trabalho de Carey (1998), em que duas características são indicadas: participação e proximidade. Participação é o percentual de legisladores que votam em uma votação nominal e proximidade é a diferença absoluta entre o percentual de legisladores que decidem votar sim e o percentual de legisladores que decidem votar não. Pode-se expressar o índice de relevância da seguinte forma:

$$
\begin{gathered}
\text { Índice de relevância de Carey }=\% \text { de legisladores que } \\
\text { votam } x \text { (1-[\% de sim - \% de não]). }
\end{gathered}
$$

Neste trabalho, apenas as votações nominais em que o índice de relevância alcançou o limiar de 0,4 foram consideradas relevantes. Note que o limite de 0,4 denota que, para cada votação considerada, pelo menos $60 \%$ dos legisladores estiveram presentes e uma maioria de dois terços derrotou uma minoria de um terço. A utilização desse critério indica a existência de 213 votações relevantes no primeiro período e 259 durante o segundo. Assim, a variável lealdade partidária mostra a taxa pela qual um deputado apoiou a posição majoritária de sua bancada em votações cruciais ocorridas em plenário. Os dados das votações nominais foram coletados do Diário do Congresso Nacional, do Banco de Dados Legislativos / CEBRAP e de Nicolau (1999).

11. Os resultados expostos nas Tabelas 5 e 6 referem-se aos modelos que melhor explicaram a variância da variável dependente. 


\section{REFERÊNCIAS BIBLIOGRÁFICAS}

ABRANCHES, Sérgio Henrique H. de. (1988), “Presidencialismo de Coalizão. O Dilema Institucional Brasileiro". Dados, vol. 31, no 1, pp. 5-38.

AMES, Barry. (1995), “Electoral Rules, Constituency Pressures, and Pork Barrel: Bases of Voting in the Brazilian Congress". The Journal of Politics, vol. 57, nํ2, pp. 324-343.

. (2000), The Deadlock of Democracy in Brazil: Interests, Identities and Institutions in Comparative Perspective. Ann Arbor, The University of Michigan Press.

AMORIM NETO, Octavio. (1994), “Formação de Gabinetes Presidenciais no Brasil: Coalizão versus Cooptação". Nova Economia, vol. 4, no 1, UFMG, pp. 9-34.

. (1998), Of Presidents, Parties, and Ministers: Cabinet Formation and Legislative Decision-Making under Separation of Powers. Ph.D. Dissertation, University of California, San Diego.

e SANTOS, Fabiano. (2001), “The Executive Connection: Patronage and Party Discipline in Brazil". Party Politics, vol. 7, no 2.

CÂMARA DOS DEPUTADOS. (1955), Regimento Interno da Câmara dos Deputados. Brasília, Gráfica do Senado. . (1994), Regimento Interno da Câmara dos Deputados. Brasília, Gráfica do Senado.

CAMPANHOLE, Adriano e CAMPANHOLE, Hilton L. (1986), Constituições do Brasil: Compilação e Atualização de Fontes. São Paulo, Atlas.

CAREY, John. (1998), Electoral Reform and the Chilean Legislative Party System. Manuscrito.

CARVALHO, Maria Isabel Valladão. (1977), A Colaboração do Legislativo para o Desempenho do Executivo durante o Governo JK. Dissertação de Mestrado, IUPERJ, Rio de Janeiro.

COX, Gary e MCCUBBINS, Mathew D. (1993), Legislative Leviathan: Party Government in the House. Berkeley, University of California Press.

Dados Estatísticos do TSE. Brasília, Tribunal Superior Eleitoral.

Deputados Brasileiros: 1826-1976. Brasília, Centro de Documentação e Informação da Câmara dos Deputados.

Deputados Brasileiros - Repertório Biográfico. Brasília, Centro de Documentação e Informação da Câmara dos Deputados, 5 vols.

FIGUEIREDO, Argelina Cheibub. (2000), Government Performance in Multiparty Presidential Systems: The Experiences of Brazil. Trabalho apresentado no XVIII World Congress of Political Science, International Science Association - ISA, Québec, 1-5 de agosto.

e LIMONGI, Fernando. (1995), “Mudança Constitucional, Desempenho do Legislativo e Consolidação Institucional". Revista Brasileira de Ciências Sociais, ano 10, no 29 , pp. $175-200$.

(1999), Executivo e Legislativo na Nova Ordem Constitucional. Rio de Janeiro, Fundação Getulio Vargas Editora. 
FLEISCHER, David. (1981), Deputados Brasileiros - Repertório Biográfico dos Senhores Deputados Abrangendo o Período de 1946-1967. Brasília, Centro de Documentação e Informação da Câmara dos Deputados.

GEDDES, Barbara. (1994), Politician's Dilemma: Building State Capacity in Latin America. Berkeley, University of California Press.

HUBER, John. (1996), Rationalizing Parliament: Legislative Institutions and Party Politics in France. Cambridge, Cambridge University Press.

LAFER, Celso. (1970), The Planning Process and the Political System in Brazil: A Study of Kubitschek's Target Plan:1956-1961. Ph.D. Dissertation, Cornell University.

LAMOUNIER, Bolivar. (1991), "Parlamentarismo, Sistema Eleitoral e Governabilidade". Nova Economia, vol. 2, no 2, UFMG, pp. 9-25.

MAINWARING, Scott. (1997), "Multipartism, Robust Federalism, and Presidentialism in Brazil", in S. Mainwaring e M. S. Shugart (eds.), Presidentialism and Democracy in Latin America. New York, Cambridge University Press.

. (1999), Rethinking Party Systems in the Third Wave of Democratization: The Case of Brazil. Stanford, Stanford University Press.

MENEGUELlO, Rachel. (1998), Partidos e Governos no Brasil Contemporâneo (1985-1997). São Paulo, Paz e Terra.

NICOLAU, Jairo M. (1999), Banco de Votações Nominais durante o Primeiro Governo Fernando Henrique Cardoso. IUPERJ, Rio de Janeiro.

. (2000), “Disciplina Partidária e Base Parlamentar na Câmara dos Deputados no Primeiro Governo Fernando Henrique Cardoso (1995-1998)". Dados, vol. 43, no 4, pp. 709-735.

PEREIRA, Carlos. (2000), What Are the Conditions for the Presidential Success in the Legislative Arena? The Brazilian Electoral Connection. Ph.D. Dissertation, The New School University, New York.

_e MUELLER, Bernardo. (2000), “Uma Teoria da Preponderância do Poder Executivo: O Sistema de Comissões no Legislativo Brasileiro". Revista Brasileira de Ciências Sociais, vol. 15, no 43, pp. 45-68.

PESSANHA, Charles. (1997), Relações entre os Poderes Executivo e Legislativo no Brasil: 1946-1994. Tese de Doutorado, USP, São Paulo.

SAMUELS, David J. (1998), Careerism and its Consequences: Federalism, Elections, and Policy-Making in Brazil. Ph.D. Dissertation, University of California, San Diego.

SANTOS, Fabiano. (1995), “Microfundamentos do Clientelismo Político no Brasil: 1959-1963". Dados, vol. 38, no 3, pp. 459-496.

. (1997), “Patronagem e Poder de Agenda na Política Brasileira". Dados, vol. 40, nº 3, pp. 465-492.

. (2000), “Deputados Federais e Instituições Legislativas no Brasil: 1946-99", in R.

Boschi, E. Diniz e F. Santos, Elites Políticas e Econômicas no Brasil Contemporâneo. São Paulo, Fundação Konrad-Adenauer, Série Pesquisas, no 18. 
SANTOS, Wanderley Guilherme dos. (1986), Sessenta e Quatro: Anatomia da Crise. São Paulo, Vértice.

\section{ABSTRACT \\ Parties and Committees in the Coalition Presidential System}

This article argues that the Brazilian President's lawmaking powers, especially related to budget-making, crucially modify the incentives for more or less cooperative behavior among House members vis-à-vis their respective party representations in Congress, comparing the two democratic periods in Brazil: 1946-64 and post-1988. During the former period, given the President's reduced agenda powers, Congress had greater freedom to define its approach to the President's policy program without running the risk of retaliation in the form of lost patronage and budget resources. During the post-1988 period, since budget-making initiative is concentrated in the hands of the Executive Branch, the President's bargaining power has expanded, requiring Congress to organize in more disciplined parties in order to more efficiently pressure the Administration to comply with agreements for mutual support. The study's empirical section begins by identifying the pattern of coalitions that allowed for the developmentalist project in the 1950s as contrasted with the partisan coalition pattern that approved the constitutional reforms during the Cardoso Administration. The second section analyzes the parties' policies towards the composition of crucial standing committees, demonstrating the impact of party loyalty on obtaining seats in the Committee on the Constitution and the Judiciary and the Committee on Finances and Taxation. The impact of party loyalty was significant in the former period and non-significant in the latter.

Key words: parties; committees; presidentialism coalition 
RÉSUMÉ

Partis et Commissions dans le Présidentialisme de Coalition

Dans cet article, on soutient que les pouvoirs législatifs du Président de la République, surtout les pouvoirs concernant le budget, influent de façon décisive sur les incitations à un comportement plus ou moins coopératif de la part des députés par rapport à leurs partis quand on compare deux périodes démocratiques au Brésil: 1946-1964 et l'après 1988. Dans la première période, en raison des pouvoirs réduits d'imposer un calendrier par le président, les législateurs disposaient d'une plus grande liberté pour définir leur comportement face au programme politique du président sans courir le risque de subir des représailles lors de leurs demandes d'appui et de fonds budgétaires. Dans la période actuelle, compte tenu de la concentration des initiatives concernant le budget entre les mains de l'Exécutif, le pouvoir de marchandage du président grandit, ce qui oblige les députés à s'organiser de façon plus disciplinée dans les partis afin d'exercer une pression efficace sur le gouvernement pour l'accomplissement des accords établis entre eux. Dans la partie empirique de ce travail, on examine d'abord le modèle de coalitions qui a permis le projet de développement des annnées 50 par opposition au modèle de coalition défini par les partis qui a approuvé les réformes constitutionnelles de la période FHC. Ensuite, on examine la politique des partis en vue de la formation de commissions permanentes fondamentales où l'on constate l'impact de la loyauté de parti pour l'acquisition d'une place dans la CCJ et dans la CFT, de façon significative et positive dans la première période, et non significative dans la seconde période.

Mots-clé: partis; comissions; présidentialisme de coalition 